\title{
Influence of Binder Dosage on Granule Structure and Packed Bed Properties in Iron Ore Sintering Process
}

\author{
Hao ZHOU, ${ }^{1) *}$ Mingxi ZHOU, ${ }^{1)}$ Damien Paul $\mathrm{O}^{\prime} \mathrm{DEA}^{2}{ }^{2)}$ Benjamin George ELLIS, ${ }^{2)}$ Jianzhong CHEN ${ }^{1)}$ and \\ Ming $\mathrm{CHENG}^{1)}$ \\ 1) State Key Laboratory of Clean Energy Utilization, Institute for Thermal Power Engineering, Zhejiang University, Hangzhou, \\ 310027 P.R. China. \\ 2) BHP Billiton, Brisbane, Qld 4000 Australia.
}

(Received on May 19, 2016; accepted on July 4, 2016; J-STAGE Advance published date: September 28, 2016)

\begin{abstract}
This paper investigates the influence of binder dosage on the iron ore sintering process. The granule structure and packed bed properties were explored under a wide range of water and hydrated lime addition levels. At the same moisture content, the addition of more hydrated lime improved the granulation efficiency by forming a more cohesive initial layer on the surface of nuclei particles and producing more agglomeration during granulation. The bed voidage-moisture curve could be divided into three regions, and this curve became flatter with higher hydrated lime addition level. A more mechanistic model of bed voidage $\left[\varepsilon=\varepsilon_{0}+\left(1-\varepsilon_{0}\right) \exp \left(-m R^{-n}\right), \quad \varepsilon_{0}=0.36 \times\left(e^{\sigma}\right)^{-0.3209}\right]$ was proposed which represents the influence of cohesive forces and potential for granule deformation by linking voidage to the spread of granule size distribution $(\sigma)$ as well as the adhering mass ratio (R). For the tested Asia-Pacific region ore blend, adding hydrated lime improved the bed permeability significantly due to the increase in granule size and bed voidage. However, there is a saturation value of solid binder dosage. The improving action becomes limited at $3 \mathrm{wt} \%$ since further increase of hydrated lime addition had no further benefit to bed voidage.
\end{abstract}

KEY WORDS: binder; iron ore sintering; granule structure; voidage; bed permeability.

\section{Introduction}

In the Asia-Pacific region, countries including China, Japan, India and Korea produced about $65 \%$ of world crude steel in 2014. Sinter constitutes around $80 \mathrm{wt} \%$ of the ferrous charge for blast furnace in these countries. ${ }^{1)}$ In the sintering process, raw materials including iron ores, fluxes and fuel need to be granulated first, since the characteristics of raw materials are very distinct from each other. For example, some iron ores are quite coarse particles more than $5 \mathrm{~mm}$ while magnetite concentrates are quite fine particles at the scale of micrometer. Some porous ores are hydrophilic and have large water absorption while coke particles are quite hydrophobic. The resulting granules with proper size and strength are then packed onto a moving strand. The formed packed bed properties would determine the airflow rate through sinter bed and convective heat transfer in flame front. These influence the flame front speed and bed temperature profiles down the sinter bed, which are especially important for the sinter productivity and final sinter yield and quality. ${ }^{2,3)}$

Both granulation and particle packing are well-established topics in the field of powder technology and many researchers have done a lot of work on those two topics

\footnotetext{
* Corresponding author: E-mail: zhouhao@zju.edu.cn

DOI: http://dx.doi.org/10.2355/isijinternational.ISIJINT-2016-298
}

independently. Specific to iron ore sintering, where water is generally used as binder for granulation, it is widely acknowledged that the formed granules during drum granulation have a structure of nuclei with adhering fines, though there are still disagreements about the typical sizes of nuclei and adhering fines. ${ }^{3-7)}$ Waters et al. ${ }^{8)}$ established a simple population balance model of sintering granulation using a partition coefficient to define the probability of a certain size fraction acting as nuclei, which was found to be useful for a wide range of iron ores. ${ }^{9)}$ In their model, the partition curve is mainly determined as a function of water content. In practice, some reactive burnt limes are found to act as binder also and the improvement of granulation efficiency varies greatly with the reactivity of burnt lime. ${ }^{7)}$ However, how the dosage of solid binder rather than water affects the granulation process in sintering was not discussed effectively before. $^{10)}$

In addition, packed bed properties such as bed voidage and bed permeability in sintering have attracted many researchers and extensive studies concerning ore properties have been done. Venkataramana et al. ${ }^{11)}$ proposed a statistical model linking bed voidage to the spread of the granule size distribution and feed specifications including $0.015 \mathrm{~mm}$ fines, water and lime contents. Khosa et al. ${ }^{12)}$ developed a simple model to predict optimal bed permeability using ore size distribution and chemical composition including LOI, $\mathrm{SiO}_{2}$, and $\mathrm{Al}_{2} \mathrm{O}_{3}$ content. Their fitted correlation could only 
be used for the single ore blends studied, and this differs markedly from ore blends used in actual production. In terms of the packing mechanism, the studies of Hinkley et $a l .{ }^{13)}$ reported that the mechanism of tightening size distribution increases bed voidage and the mechanism of granule deformation decreases bed voidage. ${ }^{14)} \mathrm{Xu}$ et $a{ }^{1{ }^{15)}}$ suggested another two mechanisms governing the packing of iron ore fines; granule density and inter-particle friction. Their experiments showed that the granule deformation becomes effective when moisture is larger than a critical value. Under given packing conditions, the packed bed properties are significantly dependent on particle properties such as size, size distribution, shape etc. ${ }^{16,17)}$ Therefore, it is necessary to discuss the granulation and packing together. Unfortunately, there has not been much in-depth research work on this complicated process in sintering so far.

In the present work, to simplify the cases, fine hydrated lime was used directly as a solid binder and 32 granulation experiments were done to investigate the influence of binder usage on the granular structure and packed bed properties of a typical Asia-Pacific region ore blend. A more theoretical correlation linking bed voidage to granular structure parameters was proposed and the reasons why granulation efficiency and bed permeability improve with more binder addition were discussed specifically.

\section{Experimental}

\subsection{Raw Materials}

To ensure good repeatability of experiments, all the raw materials were divided by rotary sample divider first to ensure homogeneity for every test. Table 1 gives the size distributions of the raw materials used including five ores, fluxes, coke and return fines. The tested five ores have quite a wide spread size distribution from 0 to $9 \mathrm{~mm}$. The limestone, serpentine as well as dolomite are all crushed to -3 $\mathrm{mm}$ while both the coke and return fines are below $5 \mathrm{~mm}$. Burnt lime is often used in sinter plants but its granulation effectiveness varies depending on its water slaking reactivity. The binder used in this study was a high-grade, fine powder hydrated lime $(72.7 \% \mathrm{CaO}, 24.3 \% \mathrm{LOI})$ rather than burnt lime. Fine powder hydrated lime is more suitable for

Table 1. Size distribution of raw materials (mass $\%$ ).

\begin{tabular}{crrrrrrrrrrrr}
\hline \multirow{2}{*}{ Name } & \multicolumn{6}{c}{ Cumulative mass\% passing (size in mm, dry basis) } \\
\cline { 2 - 11 } & 8.00 & 6.30 & 3.20 & 1.18 & 0.60 & 0.30 & 0.15 & 0.106 & 0.075 & 0.063 \\
\hline AUS1 fines & 95.8 & 87.9 & 64.0 & 44.4 & 35.9 & 27.4 & 16.8 & 11.8 & 8.0 & 5.9 \\
AUS2 fines & 95.9 & 91.1 & 70.8 & 51.4 & 42.0 & 32.2 & 21.0 & 15.3 & 10.5 & 7.6 \\
AUS3 fines & 81.1 & 75.3 & 56.2 & 35.3 & 23.9 & 14.0 & 7.0 & 4.7 & 3.2 & 2.4 \\
BRA1 fines & 90.8 & 87.5 & 73.7 & 56.1 & 43.8 & 29.1 & 18.5 & 15.0 & 12.9 & 9.6 \\
BRA2 fines & 92.6 & 87.6 & 68.0 & 51.9 & 45.4 & 39.8 & 31.8 & 25.8 & 20.1 & 15.6 \\
Limestone & 100.0 & 99.9 & 90.0 & 51.2 & 34.9 & 23.9 & 16.9 & 14.0 & 11.8 & 8.8 \\
Serpentine & 100.0 & 100.0 & 99.9 & 94.3 & 38.4 & 20.7 & 10.2 & 4.6 & 2.8 & 1.7 \\
Dolomite & 100.0 & 100.0 & 99.9 & 88.6 & 56.0 & 40.5 & 22.1 & 14.2 & 12.5 & 1.8 \\
Coke & 99.4 & 98.2 & 73.0 & 41.6 & 26.8 & 15.2 & 7.7 & 5.3 & 3.8 & 2.9 \\
Return Fines & 100.0 & 100.0 & 75.4 & 20.2 & 13.4 & 8.0 & 4.6 & 2.9 & 1.5 & 0.7 \\
\hline
\end{tabular}

laboratory studies because its effectiveness as a binder is less variable than reactive burnt lime, it is easier to handle and has lower health and safety risks. The hydrated lime powder size was analyzed by laser particle analyzer with the following results: mean volume diameter is $12.66 \mu \mathrm{m}$ $(25 \%<7.42 \mu \mathrm{m}, 50 \%<14.26 \mu \mathrm{m}, 95 \%<22.73 \mu \mathrm{m})$. The porosity of the hydrated lime was measured by mercury porosimetry AutoPore IV 9500 with the following results: total intrusion volume is $1.336 \mathrm{~mL} / \mathrm{g}$. Average pore diameter is $0.935 \mu \mathrm{m}$. Apparent density is $1.759 \mathrm{~g} / \mathrm{ml}$.

\subsection{Granulation}

An ore blend representative of those used in the AsiaPacific region was studied for the granulation process (AUS1 fines $16.7 \mathrm{wt} \%$, AUS2 fines $16.7 \mathrm{wt} \%$, AUS3 fines $33.3 \mathrm{wt} \%$, BRA1 fines $16.7 \mathrm{wt} \%$, BRA2 fines $16.7 \mathrm{wt} \%){ }^{18)}$ The fluxes were set as shown in Table 2 so that the base raw mix would make a sinter product with a target chemistry typical of sintering operations (basicity $1.90, \mathrm{TFe} \sim 56.5 \%$, $\mathrm{SiO}_{2} 5.0 \%, \mathrm{Al}_{2} \mathrm{O}_{3} \sim 1.80 \%, \mathrm{CaO} \sim 9.50 \%, \mathrm{MgO} \sim 1.70 \%$, coke rate $4.05 \%$, return fines ratio $20 \%$ ). A total of 32 granulation experiments were done with different binder usage levels and moisture content ranging from $5 \%$ to $8 \%$ (wet basis) and the hydrated lime ranging from $0 \%$ to $4 \%$ (dry mix basis).

Figure 1 shows the steps of experimental procedure including two stage granulation process, measurements of granular characteristics and packed bed properties, and finally result collection and analysis. Details are described below.

For the granulation process, around $13.5 \mathrm{~kg}$ mixtures were introduced into a stainless steel cylindrical drum with the diameter of $500 \mathrm{~mm}$ and length of $300 \mathrm{~mm}$. All materials were dry mixed for $2 \mathrm{~min}$ before water addition and further wet granulated for $10 \mathrm{~min}$ to attain steady state. The rotation speed of the small drum was kept at $16 \mathrm{rev} / \mathrm{min}$, corresponding to a Froude number of 0.0036 and a space factor of $11 \%$. After granulation, granules were further riffled and sampled to measure their apparent density, the experimental moisture content, the size distribution and the adhering ratio of granules respectively.

Table 2. Raw materials composition of granule mix (mass\%).

\begin{tabular}{ccc}
\hline Name & \%Dry Ore Basis & \%Dry Total Basis \\
\hline AUS1 fines & 16.7 & \\
AUS2 fines & 16.7 & \\
AUS3 fines & 33.3 & \\
BRA1 fines & 16.7 & \\
BRA2 fines & 16.7 & \\
Sub-total Iron ores & 100.0 & 62 \\
Limestone & & 4.8 to 9.1 \\
Serpentine & & 0.1 to 0.4 \\
Dolomite & & 5.1 \\
Coke & & 4.05 \\
Return Fines & & 20 \\
Hydrated lime & & 0 to 4 \\
\hline
\end{tabular}




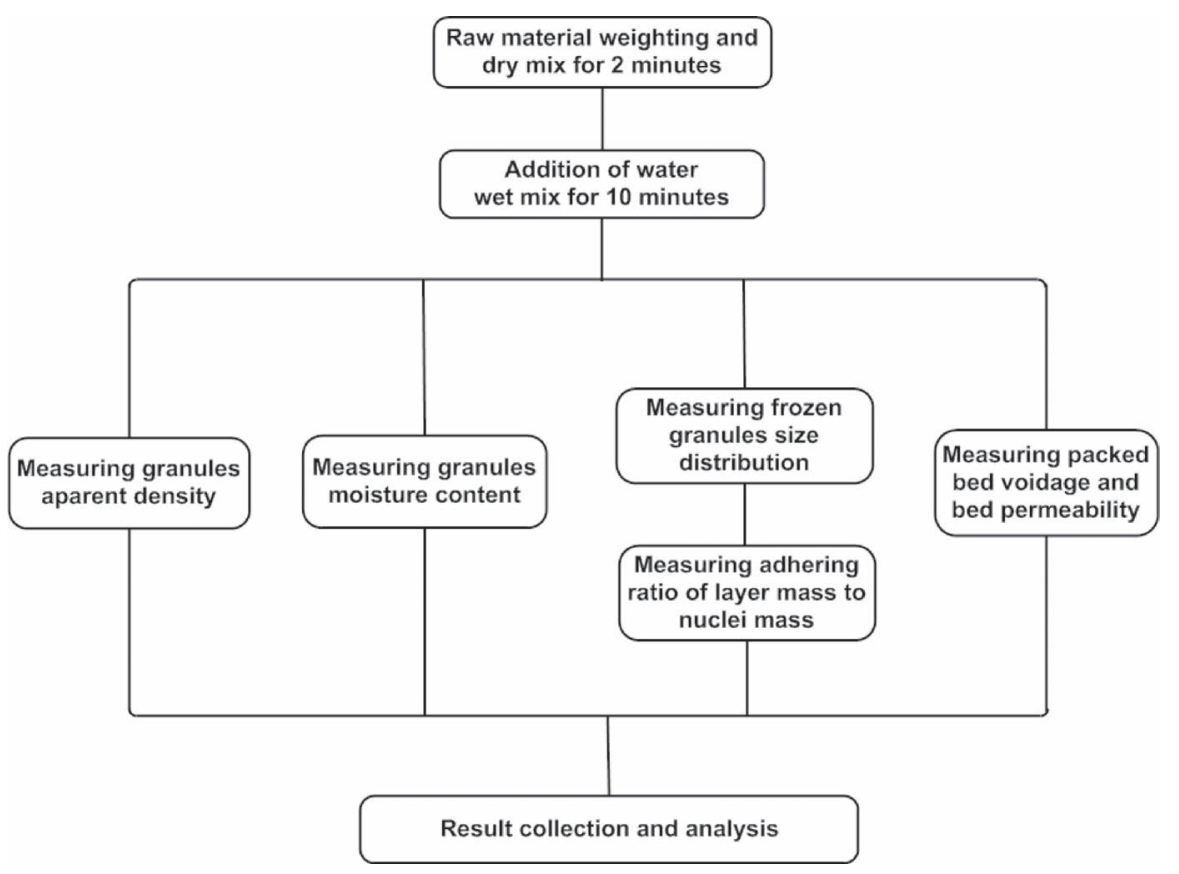

Fig. 1. Schematic view of experimental process.

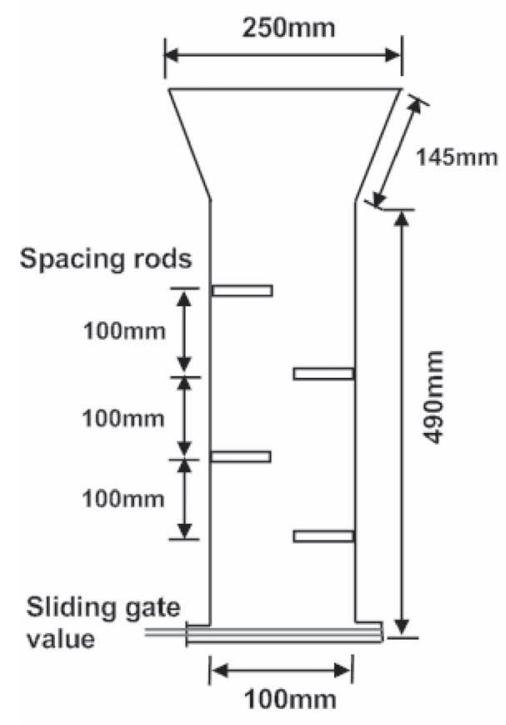

Loading part

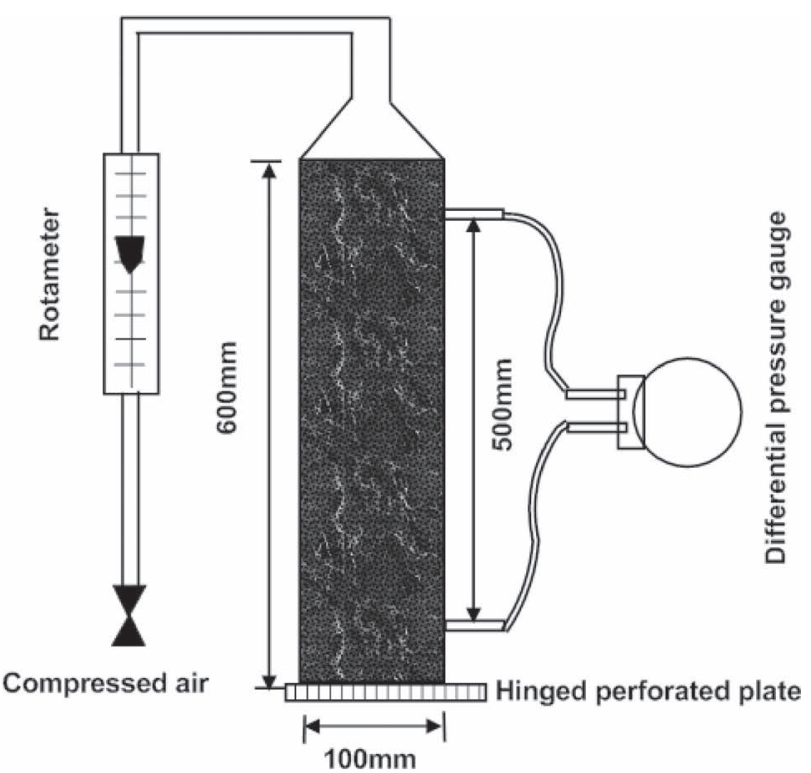

Permeability pot

Fig. 2. Schematic view of permeability pot.

The granule apparent density was determined by the kerosene displacement method while the experimental moisture was calculated by the mass difference before and after drying about $1 \mathrm{~kg}$ granules at $105^{\circ} \mathrm{C}$ in an oven for 6 hours. For measuring the size distribution of granules, to avoid the degradation of granules, around $0.5 \mathrm{~kg}$ granules were frozen with liquid nitrogen first, then poured over a geometric $\sqrt{2}$ series of sieves ranging from $0.25 \mathrm{~mm}$ to 11.2 $\mathrm{mm}$ and vibrated on a ro-tap sieve shaker for $1 \mathrm{~min}$, then each size fraction was weighted. Assuming particles of $i$ th size fraction acting as nuclei would be found in the screens of $i$ th and $(i+1)$ th, the partition coefficient for the $i$ size fraction was determined according to the granulation model developed by Waters et al. ${ }^{8)}$ as:

$$
\partial_{i}=\frac{m_{i i}+m_{i i+1}}{\sum_{j=1}^{n} m_{i j}}
$$

Where $m_{i j}$ is the mass of granules of $i$ th size fraction found in particles of $\mathrm{j}$ th size fraction.

To obtain the adhering mass ratio and experimental partition curve, each granule size fraction from frozen sizing was wet screened at $63 \mu \mathrm{m}$ followed by dry sizing of the $+63 \mu \mathrm{m}$ portion.

\subsection{Permeability Pot Tests}

Around $9 \mathrm{~kg}$ granules were used for the permeability 
pot tests to characterize the packed bed voidage and permeability for a typical granulation condition. The packing apparatus consisted of a loading device and a permeability pot, as shown in Fig. 2. The granules were poured into the loading device first, then the loading device was positioned on the top of the open permeability pot. By pulling open the sliding gate value, the granules were loaded into the permeability pot to form a random packing. Compressed air was forced to pass through the bed after sealing the permeability pot and the air flow rates at bed pressure drops of $4 \mathrm{kPa}$ and $6 \mathrm{kPa}$ of the $500 \mathrm{~mm}$ packed bed were recorded. This packing process was repeated and the mean value was reported in the results.

Bed voidage is calculated by measuring the in situ bulk density and apparent density of the granules.

$$
\varepsilon=1-\frac{\rho_{b}}{\rho_{p}}
$$

Where $\varepsilon$ is the packed bed voidage, $\rho_{b}$ and $\rho_{p}$ are the bulk density and the granule apparent density respectively $\left(\mathrm{kg} / \mathrm{m}^{3}\right)$.

The packed bed permeability is quantified by the widely accepted Japanese Permeability Units (JPU) with the following equation:

$$
J P U=\frac{Q}{A}\left(\frac{L}{\Delta P}\right)^{0.6}
$$

Where $Q$ is the air flow rate through bed $\left(\mathrm{m}^{3} / \mathrm{min}\right), L$ is the bed height $(\mathrm{mm}), A$ is the bed cross sectional area $\left(\mathrm{m}^{2}\right)$ and $\Delta P$ is the bed pressure drop $\left(\mathrm{mm} \mathrm{H}_{2} \mathrm{O}\right)$.
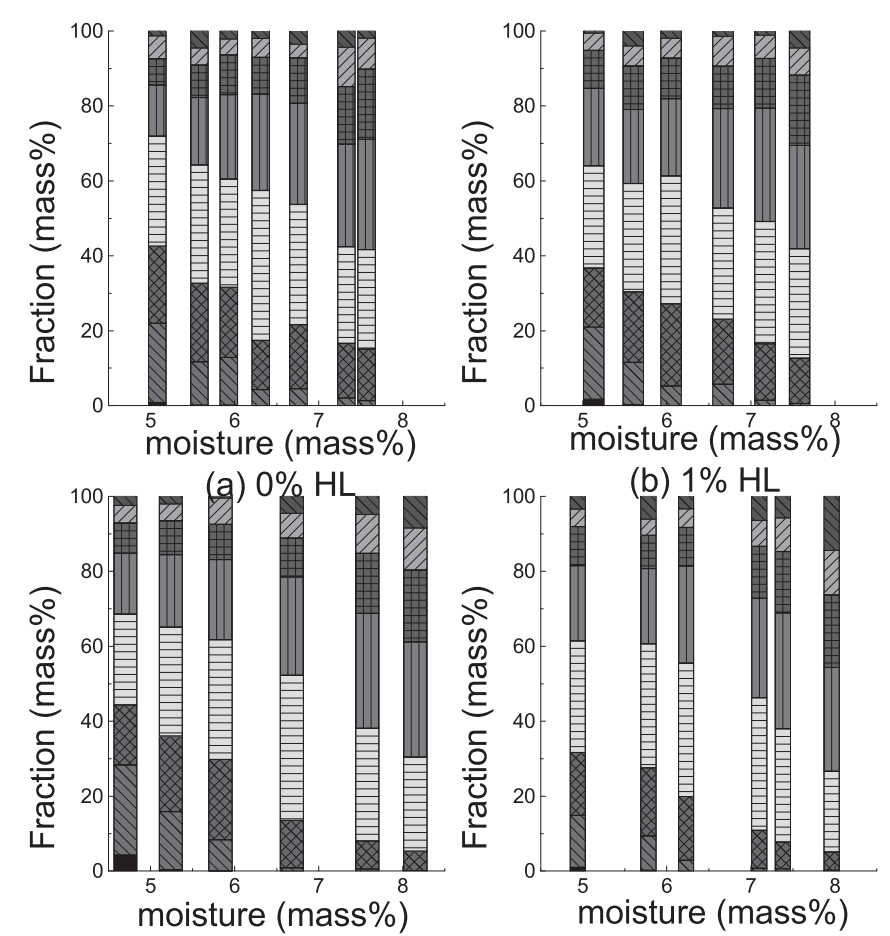

(d) $3 \% \mathrm{HL}$

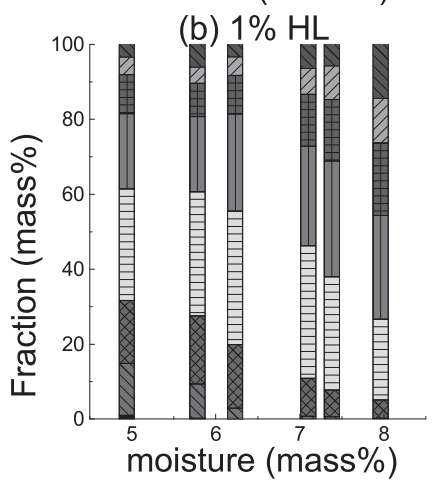

(e) $4 \% \mathrm{HL}$

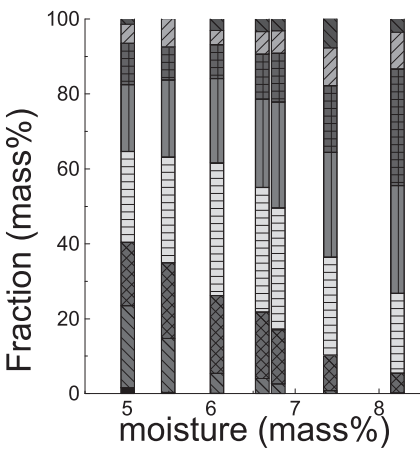

(c) $2 \% \mathrm{HL}$

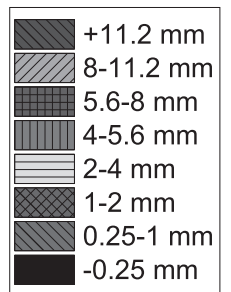

(a) Size distributions at different moisture and hydrated lime levels

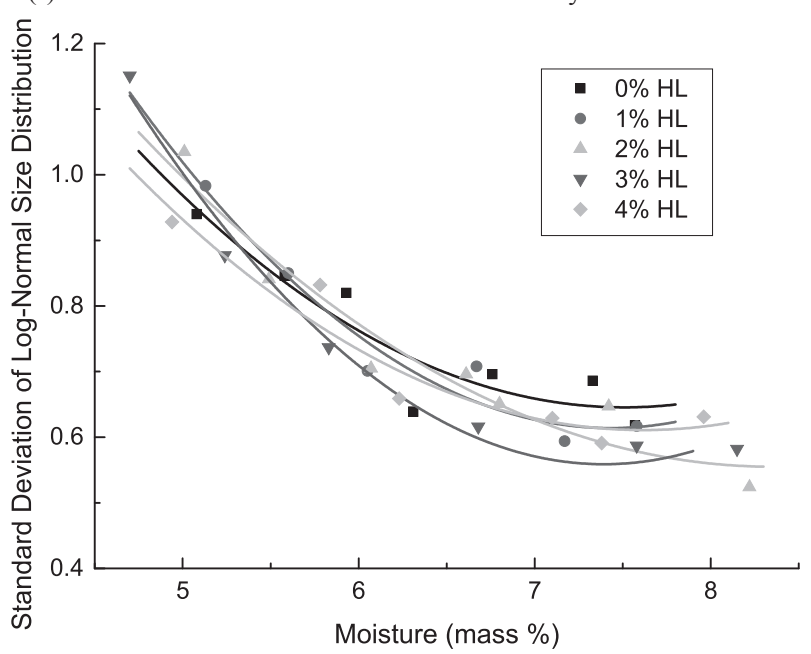

(b) Size standard deviation versus granule moisture

Fig. 3. Size distribution of granules versue moisture content for hydrated lime addition level $0 \%-4 \%$. 


\section{Results and Discussions}

\subsection{Granule Properties}

Figure 3 shows the granule size distribution with various moisture content and hydrated lime addition levels. Whatever the hydrated lime addition level is, the spread of size distribution initially becomes narrower rapidly as the moisture content is increased, and reaches a relatively constant value of around 0.6 with higher moisture contents. As the main aim of the granulation process is to get a size enlargement of raw materials, the Sauter mean diameter of granules was calculated from the size distribution as:

$$
d_{p}=\frac{1}{\sum_{i} \frac{x_{i}}{\bar{d}_{i}}}
$$

Where $\bar{d}_{i}$ is the mean size of size interval $i$ and $x_{i}$ is the mass fraction in size interval $i$.

It can be seen from Fig. 4 that the SMD of granules increases almost linearly with the increase of moisture, from $\sim 1 \mathrm{~mm}$ at $5 \mathrm{wt} \% \mathrm{H}_{2} \mathrm{O}$ to $\sim 4 \mathrm{~mm}$ at $8 \mathrm{wt} \% \mathrm{H}_{2} \mathrm{O}$. The slope of the fitted line becomes steeper as the HL level is increased in the blend. A small increase in binder dosage can therefore lead to a significant increase in granulation effectiveness.

During granulation, particles are mostly held together by liquid bridges formed from sprayed water. When the added water content is small, water cannot fill all of the voids, and granule growth would occur mostly by nucleation with a thin adhering layer and little agglomeration happens due to insufficient binder being present on the surface of particles. ${ }^{10)}$ With the increase of water addition, liquid bridges would exist, changing from the pendular state to the funicular state and then to the capillary state agglomeration would become significant and a thicker adhering layer would be formed. ${ }^{19)}$ Some $4-5.6 \mathrm{~mm}$ granules were mounted in resin and observed by optical microscopy - the pictures are shown in Fig. 5. Obviously, the granules have a structure of nuclei with an adhering layer. The thickness of the adhering layer increases with the increase in moisture from Figs. 5(a) to $5(\mathrm{c})$, as well as the size of particles in the adhering layer. Comparing the $0 \%$ HL case in Fig. 5(d) with the 3\% HL example in Fig. (c) it can be seen that the thickness of the adhering layer also significantly increases with the addition of HL. Since some small voids may exist in the adhering layer, a thicker adhering layer would lead to the decrease of granule apparent density, generally from $\sim 3200 \mathrm{~kg} / \mathrm{m}^{3}$ at

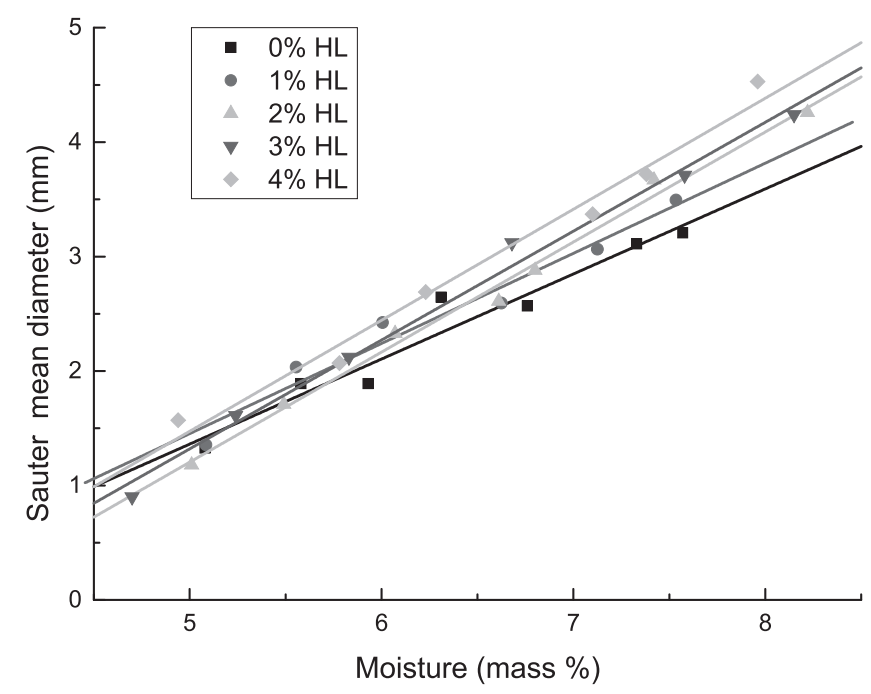

Fig. 4. Sauter mean diameter versue moisture content.

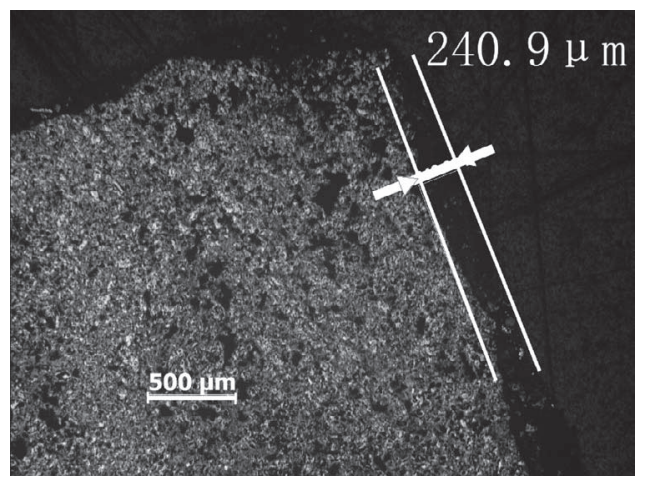

(a) $3 \%$ HL blend $4.76 \%$ moisture

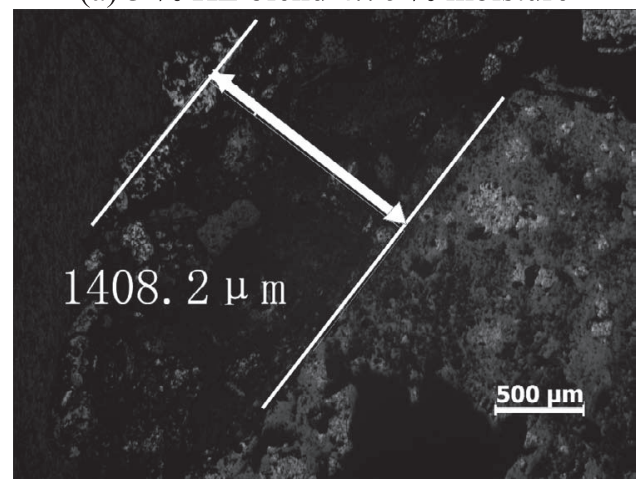

(c) $3 \%$ HL blend $7.57 \%$ moisture

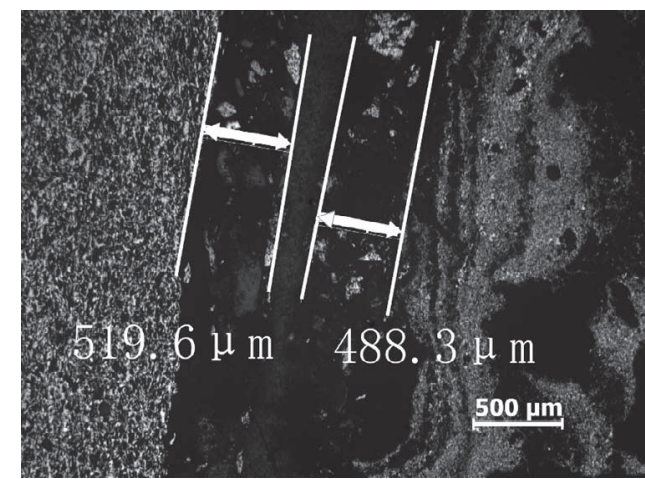

(b) $3 \%$ HL blend $5.83 \%$ moisture

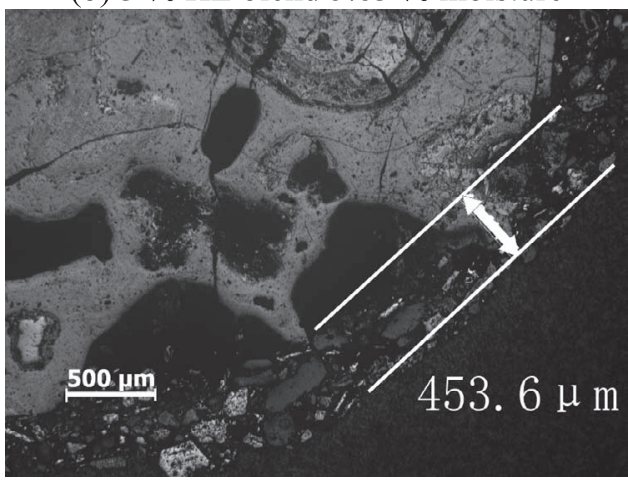

(d) $0 \%$ HL blend $6.31 \%$ moisture

Fig. 5. Pictures of adhering layer of granules. 
$5 \mathrm{wt} \% \mathrm{H}_{2} \mathrm{O}$ to $\sim 2950 \mathrm{~kg} / \mathrm{m}^{3}$ at $8 \mathrm{wt} \% \mathrm{H}_{2} \mathrm{O}$.

According to the partition curve, the particle size which has a partition coefficient of 0.5 means the particle size where $50 \%$ of particles are nuclei, namely the cut-off size between adhering and nuclei particles. This index $x_{0.5}$ can be used to represent the effectiveness of the whole granulation process. Figure 6 takes the 4\% HL blend as an example and shows the method to determine $x_{0.5}$ by fitting the experimental partition coefficient to a log normal function. The $x_{0.5}$ under different binder dosage conditions is shown in Fig. 7. It can be seen that $x_{0.5}$ is linked proportionally to the moisture content and increases more rapidly with more HL added in the blend. Previous studies showed that the granulation process in iron ore sintering is a two stage auto-layering process, including an inner layer of very fine particles coated on the surface of a nuclei particle and an outer layer of some intermediate particles incorporated into the matrix of fines. ${ }^{11,14)}$ Bergstrand et al. ${ }^{20)}$ concluded that the mineralogical and textural characteristics of very fine particles $(<50 \mu \mathrm{m})$ forming the initial inner layer greatly

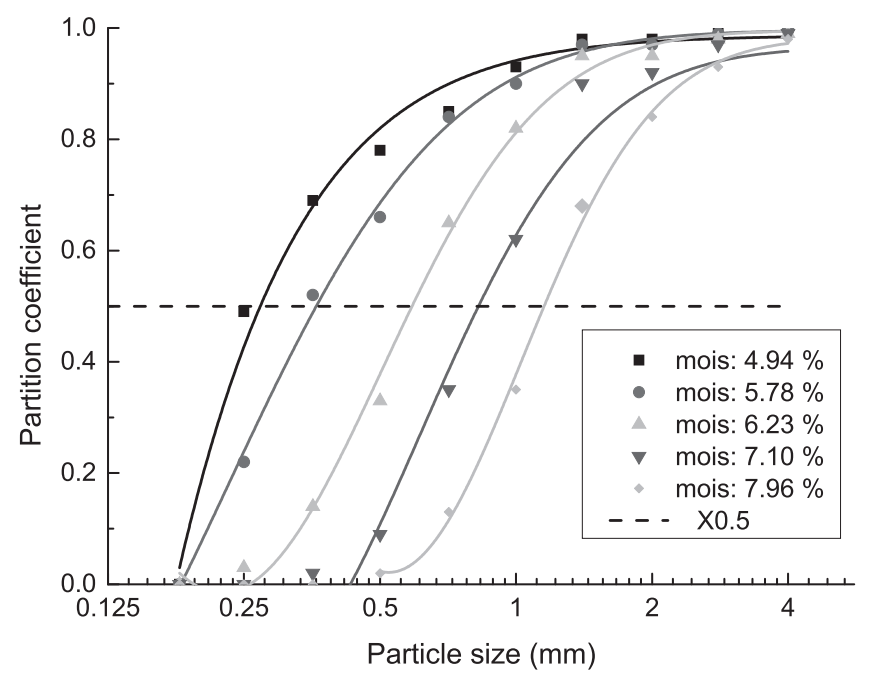

Fig. 6. Determination of $\mathrm{X}_{0.5}$ from partition coefficient curves (4\% HL blend under different moisture content conditions).

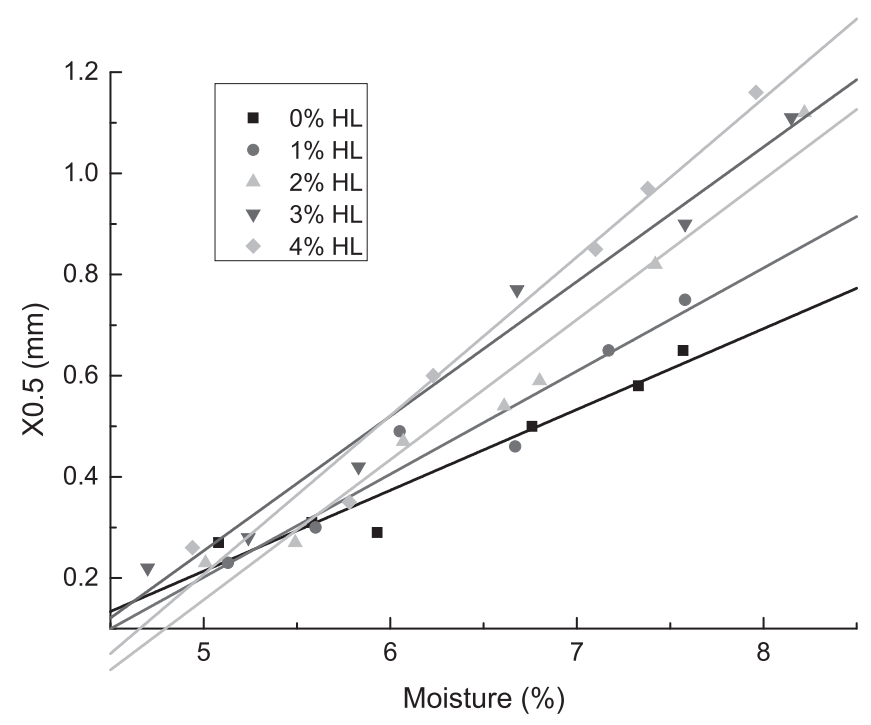

Fig. 7. $\mathrm{X}_{0.5}$ versus moisture content. affect the granulation behaviour. Kawachi et $a .^{21)}$ used some dispersants to get more micro-particles of different kinds of ores in a blend and found that the optimum amount of granulation moisture differs widely due to the different physical properties of the micro-particles of various ore types. Increasing the amount of hydrated lime in the blend favours the greater distribution of superfine particles, resulting in more agglomeration during granulation and greater granulation efficiency. Hydrated lime also has a fibrous structure and a much smaller size of $\sim 15 \mu \mathrm{m}$, which can generate a larger cohesive force to attract more intermediate sized particles to adhere in the inner layer.

\subsection{Bed Voidage}

Figure 8 shows the bed voidage curve as a function of moisture for the mixed ore blend with different levels of binder. These curves contain three regions including an initial increasing stage with low moisture, a relatively constant stage and the final decreasing stage at higher moistures, which is consistent with the previous work on single ore blends. ${ }^{14)}$ It is interesting that the $4 \%$ HL voidage curve is almost the same as 3\% HL curve, which means further increase of HL from $3 \%$ to $4 \%$ did not benefit the granule packing.

In Region 1, where bed voidage increases with moisture, the bed voidage improves as the HL addition is increased from $0 \%$ to $3 \%$. The reason why this happens may be that more micro-particles exist in the total mix or modification of the growing granule surfaces, resulting in larger cohesive forces to form higher bed voidage. ${ }^{17,22}$ However, when HL further increases from $3 \%$ to $4 \%$, this inter-particle force would not increase anymore and cannot restrict the movement of particles anymore. In Region 3, the thicker adhering layer formed in granules and the deformation of the adhering layer greatly influences voidage. The extent of this deformation depends on both the strength of granule adhering layer and the force exerted on the granules. ${ }^{14)}$ Though the apparent density of granules becomes smaller in Region 3, which may mean less compaction in the lower bed formed by the weight of granules above, the total weight of the packed granules in permeability pot increases due to the much weaker adhering fines layer during the dynamic

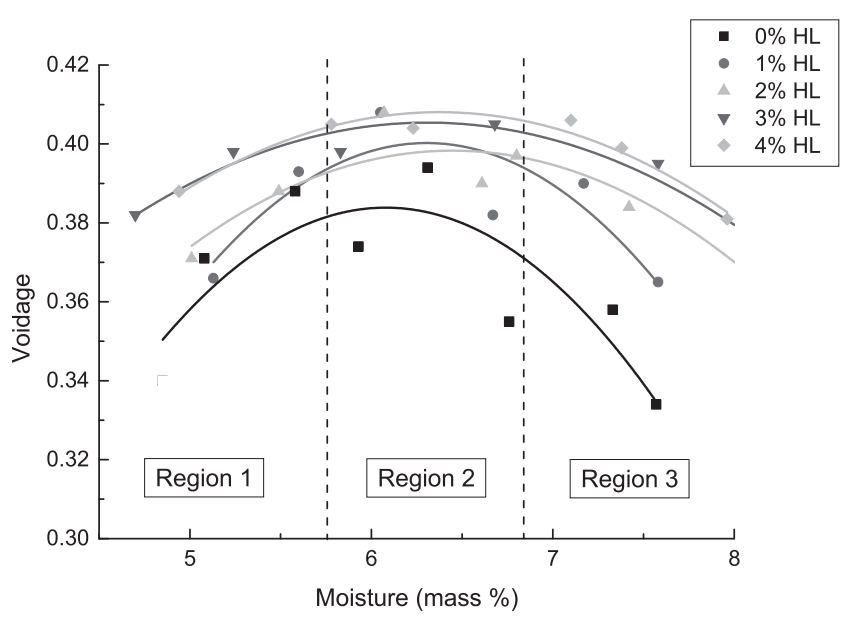

Fig. 8. Bed voidage versus moisture with different HL addition level. 
packing process. Therefore, the bed voidage decreases with increasing moisture in this region. When HL addition level increases from $0 \%$ to $3 \%$, higher bed voidage can be obtained with higher HL addition level due to a stronger adhering layer resisting deformation under load. However, the adhering layer strength of granules in $3 \%$ HL blend seems to be enough to withstand the compaction due to loading and the weight of the bed of granules. Extra increase of HL from 3\% to $4 \%$ didn't increase bed voidage any further.

Bed voidage is an important factor influencing the bed permeability. The step of charging granules into the sinter strand or permeability pot after granulation is quite a complicated process. It is a wet packing of poly-sized, deformable particles with irregular shape. Present packing theory has not been developed enough to be applied for this real situation.

Hinkley et $a l .{ }^{13)}$ reported that the thickness of adhering layer is the key factor which influences granule deformation and proposed a simple correlation linking bed voidage to the adhering mass ratio as:

$$
\varepsilon=\varepsilon^{*}+a \exp (-\mathrm{R})
$$

Where $\alpha$ is a fitted parameter, $\mathrm{R}$ is the adhering mass ratio, $\varepsilon^{*}$ is the bed voidage when $\mathrm{R}$ approaches infinity, which corresponds to a packed bed of pellets formed without nuclei particles. Their granulation experiments without solid binder showed that bed voidage decreases with the increase of $\mathrm{R}$ before levelling at an asymptotic value for large values of $\mathrm{R}$. The bed voidage for granulation experiments with HL addition is plotted against $\mathrm{R}$ in Fig. 9. When solid binder is used, though thicker adhering layer may be formed with large $\mathrm{R}$, the adhering layer would be denser and have a higher strength. The bed voidage decreases more slowly with increasing adhering mass ratio as the HL level is increased.

For a cohesive non-deformable particle system, when inter-particle forces such as capillary force by liquid addition and Van der Waals force by fine particles are introduced into powder packing, to quantify the influence of the cohesive forces on the bed voidage, some researchers ${ }^{22-24)}$ used the granular bond number to evaluate the magnitudes

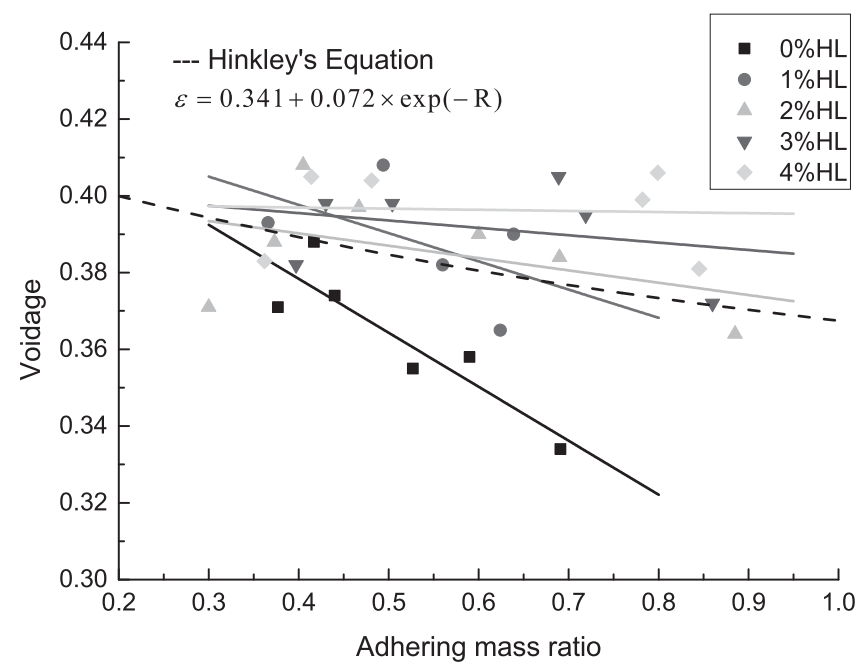

Fig. 9. Bed voidage versus adhering mass ratio. of cohesive forces and gravity as:

$$
\varepsilon=\varepsilon_{0}+\left(1-\varepsilon_{0}\right) \exp \left(-m B o_{g}^{-n}\right)
$$

Where $\varepsilon_{0}$ is the voidage of dry coarse particles, $m$ and $n$ are fitted parameters, $B o_{g}$ is the so-called granular bond number calculated by $\frac{F_{\text {inter }}}{W_{g}}$. This equation agreed well with the packing of mono-sized glass bead spheres. ${ }^{23)}$ Its form is quite similar to the former correlation by considering the deformation of the adhering layer on voidage. In the iron ore granulation process, the non-dimensional parameter of adhering mass ratio increases with more water addition as well as more micro-particles in the blend. It is reasonable to think that the adhering ratio may have the same function as the parameter $B o_{g}$. Adhering mass ratio can not only show the potential of particle deformation but also represent the cohesive forces affecting packing results. All the voidage data from this paper and references ${ }^{14)}$ were fitted by the correlation below.

$$
\varepsilon=\varepsilon_{0}+\left(1-\varepsilon_{0}\right) \exp \left(-m R^{-n}\right)
$$

In $\mathrm{Yu}$ et al. model, ${ }^{23)}$ the initial voidage $\varepsilon_{0}$ is 0.36 for random dense packing and 0.40 for random loose packing of mono-sized dry coarse spheres. Due to the compaction in a bed which is as high as $600 \mathrm{~mm}$, the granules should be a close packing rather than loose packing. Considering the wide size distribution of granules, the initial voidage $\varepsilon_{0}$ was calculated according to the correlation developed by Brouwers et al. ${ }^{25,26)}$ for dry coarse particles with lognormal size distribution below:

$$
\varepsilon_{0}=0.36 \times\left(e^{\sigma}\right)^{-0.3209}
$$

Where $\sigma$ is the lognormal standard deviation of granule size distribution.

The best fit parameters of Eq. (7) are $\mathrm{m}=2.484$ and $\mathrm{n}=-0.246$. Figure 10 shows the comparison between the predicted voidage and measured voidage. The solid black symbols are results of granulation experiments with HL in this paper while the white symbols are the results from literature work with single ore blends without solid binder. ${ }^{14)}$ Most of the predicted results are within the $\pm 10 \%$ error zone and give a correlation coefficient of 0.52 . However, the

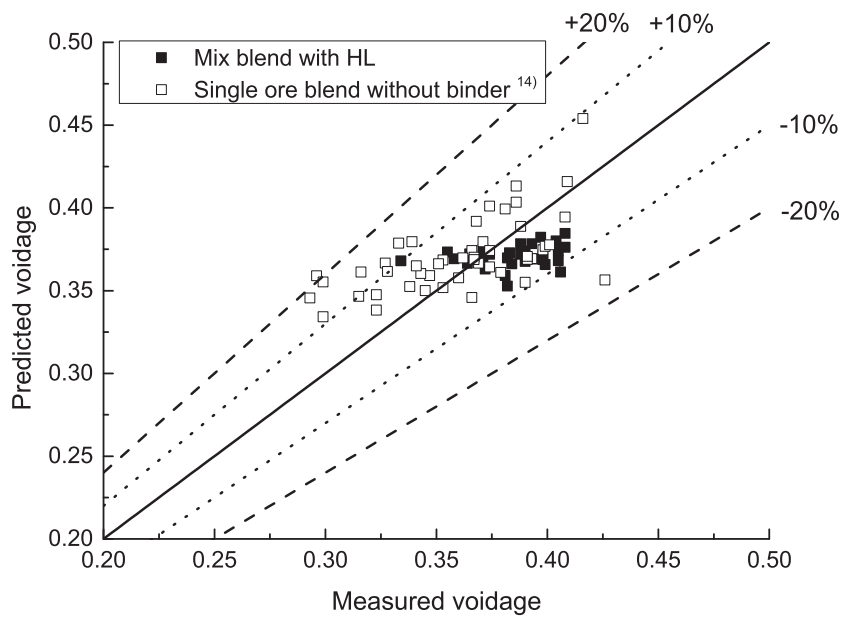

Fig. 10. Comparison between predicted and measured bed voidage. 


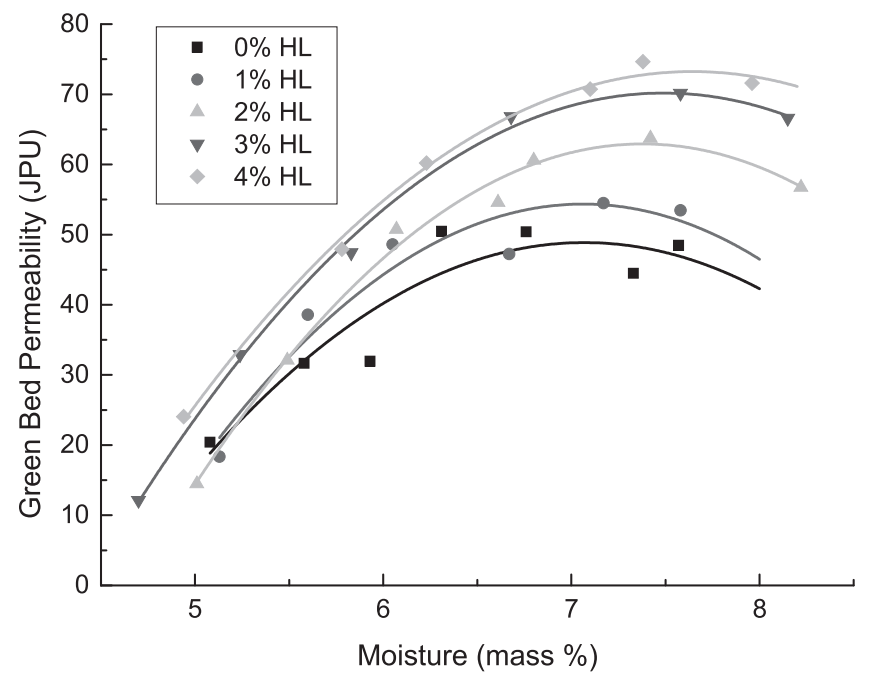

Fig. 11. JPU versus moisture with different HL addition level.

latter group are quite scattered while the former group with HL addition are clustered more tightly. It seems that this correlation is more applicable to mixed ore blends in actual production, because the characteristics of ore type dominate the adhering mass ratio in single ore blend. Clearly the HL has an additional effect on the strength of the adhering layer, and this is the subject of future work.

\subsection{Bed Permeability}

Figure 11 shows the measured bed permeability under different binder usage conditions. When HL addition level increases from $0 \%$ to $3 \%$, at the similar moisture level, the JPU of the green bed increases with the added level of HL. However, when the HL addition increases further from $3 \%$ to $4 \%$, the extent of the increase in bed permeability becomes small.

The Ergun equation has been widely accepted to explain the relationship between pressure drop and particle characteristics for a particle packed bed.

$$
\frac{\Delta P}{L}=k_{1} \frac{\mu(1-\varepsilon)^{2}}{\Phi^{2} d_{p}^{2} \varepsilon^{3}} U+k_{2} \frac{\rho(1-\varepsilon)}{\Phi d_{p} \varepsilon^{3}} U^{2}
$$

Where $\Delta P$ is the bed pressure drop (pa), $L$ is the bed height (m), $\mu$ and $\rho$ are the gas viscosity and density respectively $\left(\mathrm{pa} / \mathrm{s}, \mathrm{kg} / \mathrm{m}^{3}\right), k_{1}$ and $k_{2}$ are the viscous and inertial resistance coefficients, $\Phi$ is the particle sphericity, and $d_{p}$ is surface/volume mean size of particles (m), $U$ is the superficial gas velocity $(\mathrm{m} / \mathrm{s})$.

Using the constants of $k_{1} / \Phi^{2}=323$ and $k_{2} / \Phi=3.78$ fitted by Hinkley et l. $^{27)}$ for a wide range of moisture contents and ore blends, the effects of SMD and bed voidage on bed pressure drop when superficial gas velocity was fixed at 1 $\mathrm{m} / \mathrm{s}$ are shown in Fig. 12. On the one hand, the added HL increases the granulation efficiency as discussed above, that is to say, the SMD becomes bigger, resulting in a smaller bed pressure drop. On the other hand, the added HL also increased the bed voidage, which greatly improved the bed permeability. However, bed pressure drop is much more sensitive to bed voidage than particle diameter especially when particle size is larger than $3 \mathrm{~mm}$. So when the HL addition further increases from $3 \%$ to $4 \%$, the bed perme-

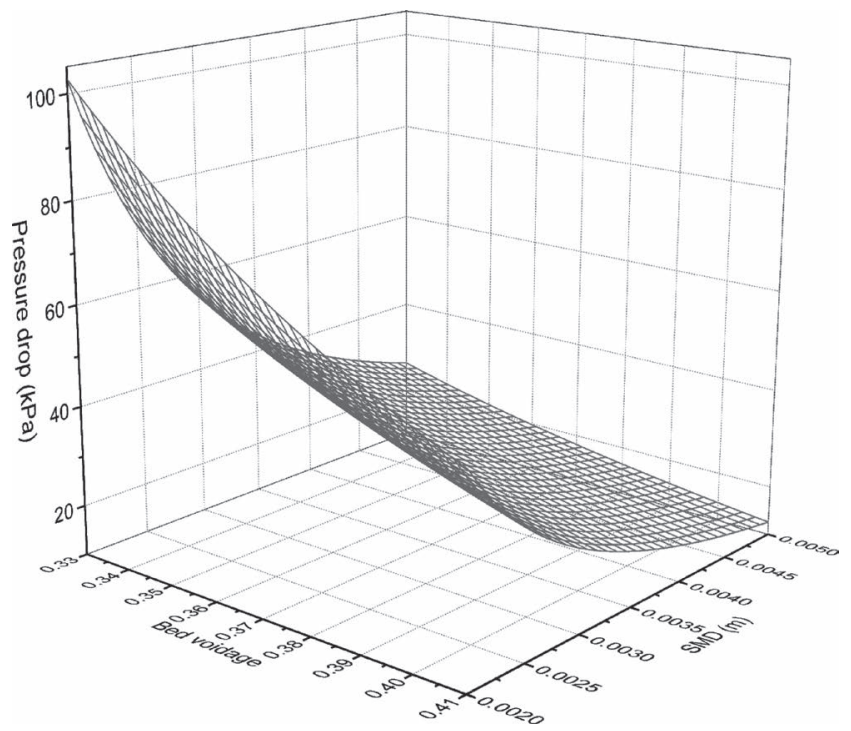

Fig. 12. Contribution of bed voidage and SMD to bed pressure drop.

Table 3. Optimum parameters at the maximum bed permeability for each $\% \mathrm{HL}$ level.

\begin{tabular}{lccccc}
\hline Hydrate lime addition level/\% & 0 & 1 & 2 & 3 & 4 \\
\hline Optimum moisture/\% & 7.06 & 7.08 & 7.39 & 7.49 & 7.64 \\
Optimum SMD/mm & 2.90 & 2.96 & 3.50 & 3.69 & 4.04 \\
Optimum Deviation & 0.656 & 0.623 & 0.591 & 0.560 & 0.610 \\
Optimum bed permeability/JPU & 48.9 & 54.4 & 62.9 & 70.2 & 73.2 \\
\hline
\end{tabular}

ability improves very little as bed voidage doesn't increase any further. Table 3 shows the optimum parameters when the bed permeability reaches a maximum for each $\% \mathrm{HL}$ case. Increasing hydrated lime addition level from $0 \mathrm{wt} \%$ to $3 \mathrm{wt} \%$ can increase the JPU value by $44 \%$. The optimum moisture for the optimum bed permeability increases slightly with the increase of HL addition. As the mercury porosimetry results shows, fine hydrated lime powder has a high particle surface area and is quite porous (see Section 2.1). Therefore some more water is needed to achieve optimum agglomeration during granulation resulting in a larger granule size with better strength.

\section{Conclusions}

The Sauter mean diameter of granules increases linearly with increases in moisture content, and it has been shown that the addition of a solid binder like hydrated lime can also improve the granulation efficiency. This is contributed to by a more cohesive inner initial layer formed on the surface of nuclei particles, resulting in more agglomeration during granulation.

The bed voidage-moisture curve has three regions. In Region 1, at low moisture, bed voidage increases because of the narrowing size distribution. In this region, the addition of hydrated lime to the blend further increases the bed voidage due to increases in the cohesive force due to the presence of micro-particles. In Region 3, at high moisture content, granule deformation is the main mechanism 
decreasing the bed voidage with increasing moisture. With a higher HL addition level, granules become less deformable due to a denser adhering layer, which has better strength. However, further increasing from 3\% HL to $4 \% \mathrm{HL}$ has no additional effect on the voidage-moisture curve. A theoretical correlation was proposed to predict bed voidage, which includes the standard deviation of granule size distribution and also the adhering mass ratio, representing the influence of cohesive forces and the potential for granular deformation. The predicted results are able to satisfactorily incorporate the effects of HL addition on voidage and are within an acceptable error margin compared to experimental results. The influence of HL on the adhering layer strength is clearly also important, and this is the subject of future work.

Introducing HL into the tested blend, which is representative of those used in the Asia-Pacific region, improved bed permeability considerably. However, there is an optimum HL level and further addition has less benefit. The improving action becomes saturated at $3 \mathrm{wt} \% \mathrm{HL}$, and further increases in HL have no additional benefit.

\section{Acknowledgments}

Financial support for this work has been provided by BHP Billiton and this is gratefully acknowledged. Financial support from National Basic Research Program of China (2015CB251501), National Natural Science Foundation of China (51476137) for Prof. Zhou is also gratefully acknowledged. The authors would also like to thank Dr. T. Honeyands (NIER, University of Newcastle, Australia) for his assistance in preparing this paper.

\section{REFERENCES}

1) The Technical Society, ISIJ. ISIJ Int., 55 (2015), 911.

2) C. E. Loo and M. F. Hutchens: ISIJ Int., 43 (2003), 630.

3) A. Formoso, A. Moro, G. F. Pello, J. L. Menendez, M. Muniz and A. Cores: Ironmaking Steelmaking, 30 (2003), 447.

4) J. Khosa and J. Manuel: ISIJ Int., 47 (2007), 965.

5) R. Venkataramana, S. S. Gupta and P. C. Kapur: Tata Search, 26 (1997), 66.

6) X. Lv, C. Bai, G. Qiu and M. Hu: Powder Technol., 204 (2010), 138.

7) L. S. Yuan, X. H. Fan, M. Gan, G. M. Yang and Y. Wang: J. Iron Steel Res. Int., 21 (2014), 905.

8) A. G. Waters, J. D. Litster and S. K. Nicol: ISIJ Int., 29 (1989), 274.

9) C. C. Ekwebelam, B. G. Ellis and T. A. G. Langrish: Asia-Pacific J. Chem. Eng., 2 (2007), 137.

10) G. I. Tardos, M. I. Khan and P. R. Mort: Powder Technol., 94 (1997), 245.

11) R. Venkataramana, S. S. Gupta and P. C. Kapur: Int. J. Miner. Process., 57 (1999), 43.

12) J. Khosa and J. Manuel: ISIJ Int., 47 (2007), 965.

13) J. Hinkley, A. G. Waters, D. O'Dea and J. D. Litster: Int. J. Miner. Process., 41 (1994), 53.

14) B. G. Ellis, C. E. Loo and D. Witchard: Ironmaking Steelmaking, 34 (2007), 99.

15) J. Q. Xu, R. P. Zou and A. B. Yu: Powder Technol., 169 (2006), 99.

16) R. P Zou, J. Q. Xu, C. L. Feng, A. B. Yu, S. Johnston and N. Standish: Powder Technol., 130 (2003), 77.

17) R. P. Zou, M. L. Gan and A. B. Yu: Chem. Eng. Sci., 66 (2011), 4711.

18) H. Zhou, M. X. Zhou, Z. H. Liu, M. Cheng, K. Z. Qiu and K. F. Cen: ISIJ Int., 55 (2015), 2556.

19) S. M. Iveson, J. D. Lister, K. Hapgood and B. J. Ennis: Powder Technol., 117 (2001), 3.

20) R. Bergstrand, J. Khosa, A. Waters and J. Garden: ISIJ Int., 45 (2005), 492.

21) S. Kawachi and S. Kasama: ISIJ Int., 49 (2009), 637.

22) M. Capece, Z. Huang, D. To, M. Aloia, C. Muchira and A. B. Yu: Powder Technol., 254 (2014), 103.

23) A. B. Yu, C. L. Feng, R. P. Zou and R. Y. Yang: Powder Technol., 130 (2003), 70.

24) A. J. Forsyth, S. R. Hutton, C. F. Osborne and M. J. Rhodes: Phys. Rev. Lett., 87 (2011), 244301.

25) H. J. H. Brouwers: Phys. Rev. E, 74 (2006), 031309.

26) H. J. H. Brouwers: Phys. Rev. E, 89 (2014), 052211.

27) J. Hinkley, A. G. Waters and J. D. Litster: Int. J. Miner. Process., 42 (1994), 37. 